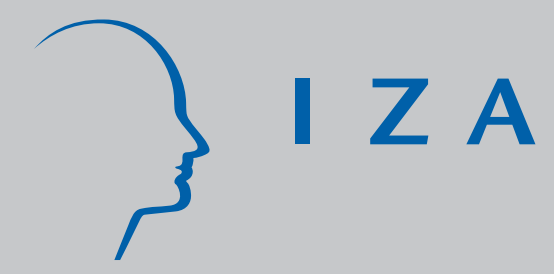

IZADP No. 1657

Increasing Returns to Education and the Skills Under-Investment Trap

Alison Booth

Melvyn Coles

July 2005 


\title{
Increasing Returns to Education and the Skills Under-Investment Trap
}

\author{
Alison Booth \\ RSSS, Australian National University \\ and IZA Bonn \\ Melvyn Coles \\ ICREA, IAE and IZA Bonn
}

Discussion Paper No. 1657

July 2005

IZA

P.O. Box 7240

53072 Bonn

Germany

Phone: +49-228-3894-0

Fax: +49-228-3894-180

Email: iza@iza.org

Any opinions expressed here are those of the author(s) and not those of the institute. Research disseminated by IZA may include views on policy, but the institute itself takes no institutional policy positions.

The Institute for the Study of Labor (IZA) in Bonn is a local and virtual international research center and a place of communication between science, politics and business. IZA is an independent nonprofit company supported by Deutsche Post World Net. The center is associated with the University of Bonn and offers a stimulating research environment through its research networks, research support, and visitors and doctoral programs. IZA engages in (i) original and internationally competitive research in all fields of labor economics, (ii) development of policy concepts, and (iii) dissemination of research results and concepts to the interested public.

IZA Discussion Papers often represent preliminary work and are circulated to encourage discussion. Citation of such a paper should account for its provisional character. A revised version may be available directly from the author. 


\section{ABSTRACT \\ Increasing Returns to Education and the Skills Under-Investment Trap*}

We model educational investment and labor supply in a competitive economy with home and market production. Heterogeneous workers are assumed to have different productivities both at home and in the workplace. We investigate the degree to which there is under-investment in human capital, and examine the deadweight losses that accrue via distortionary taxes. We show that there are increasing returns to education at the participation margin, and that deadweight losses are most severe for workers located here. Although the social planner's optimum implies the worker should choose a high level of education and participate in the market sector, instead the worker chooses not to invest in human capital and either nonparticipation or partial participation in market-sector work. A severe deadweight loss is generated by this substitution effect. Those individuals most likely to be in this trap are those types with large enough home productivity, who are likely either to be involved in home production or to be characterized by a strong preference for other non-market sector activities.

JEL Classification: H24, J13, J24, J31, J42

Keywords: home production, labor supply, returns to education, income tax

Corresponding author:

Alison Booth

Economics Program, RSSS

Coombs Building 9, Fellows Road

Australian National University

ACT 0200

Australia

Email: alison.booth@anu.edu.au

\footnotetext{
* We are grateful to the ARC for financial support under Discovery Project Grant No. DP0556740 and to Hiau Joo Kee for excellent research assistance. Melvyn Coles also thanks the Barcelona Economics Program of CREA for support.
} 


\section{Introduction}

We model educational investment and labor supply in a competitive economy with home and market production. Heterogeneous workers are assumed to have different productivities both at home and in the workplace. We investigate the degree to which there is under-investment in human capital and examine the deadweight losses accruing via distortionary taxes. We show that there are increasing returns to education at the participation margin, and that deadweight losses are most severe for workers located here. Although the social planner's optimum implies the worker should choose a high level of education and participate in the market sector, instead she chooses not to invest in human capital and either non-participation or partial participation in market-sector work. A severe deadweight loss is generated by this large substitution effect. Individuals most likely to be in this trap are those types with large enough home productivity, who are likely either to be involved in home production or to be characterized by a strong preference for other non-market sector activities. An important prediction of our model is that an increase in tax rates or social security payments reduces the returns from working longer hours and leads to lower education and participation rates.

A central feature of our approach is that workers are heterogeneous, with different productivities both in the home and in the workplace. Not surprisingly, taxes on labor market income and the presence of social security payments distort human capital investment and labor supply at all ability levels. But these losses are potentially very high for those individuals at the participation margin, who are indifferent to participating in the labor market.

Three examples illustrate our thesis. First, consider a talented home-maker with high home productivity but low workplace productivity. Such an individual is unaffected by distortionary taxation in the labor market. She will earn her marginal product in domestic production and is largely unaffected by distortions in the workplace. ${ }^{1}$ Our second illustrative example is an individual with low home productivity but high workplace productivity. Because she will be affected by labor income taxation, she will therefore invest less in labor market skills than under

\footnotetext{
${ }^{1}$ High returns to home productivity might be realized by those involved with care of young children or elderly parents, or for individuals with a taste for leisure or for home renovations, or for those with a strong aversion to workplace employment. We do not attempt to separate out these various facets of home productivity in this paper and, for simplicity, we assume away leisure from our modeling framework.
} 
the competetive situation with no income taxation. However, given her low home productivity, she will not substitute much to home production. Consequently the deadweight loss is relatively small, being a standard Harberger triangle.

But large welfare losses do arise for our third example, of workers who are relatively talented in both dimensions. Here a tax on labor income leads to large substitution effects to home production. Importantly, we also establish that there are increasing returns to education at the participation margin. These increasing returns generate an under-investment trap. In the absence of distortionary taxes, the worker would choose a high level of education and participate in full time employment. Instead income tax and social security payments lead to low education levels, and either non-participation or part-time employment. This switch implies a large deadweight loss.

Our model spans two periods. In the first phase of their lives, the young can choose to increase their future workplace ability by investing in general skills affecting their workplace productivity. Such investments may not necessarily improve future home productivity. For example, they might invest in a mathematics course or a qualification in information technology, imbuing them with expertise that is invaluable in the workplace but less likely to increase their skills at home production. Of course if labor income were not taxed, so that workers were paid their full market value, each worker would invest in general human capital at the socially optimal level. But if a worker expects to receive less than her full marginal return to human capital investment, she not only under-participates in the market sector ex post but also under-invests in human capital ex ante.

The central insight of our paper is that, around the participation margin, the endogenous labor supply decisions of workers generate increasing marginal returns to education. ${ }^{2}$ To see why, note that a worker who does not participate ex post realizes a zero return to any human capital investments. Similarly, a worker who takes part-time employment obtains a relatively limited return to any ex ante skills investment. It follows that workers who supply more labor

\footnotetext{
${ }^{2}$ Our model has some similarities to Acemoglu (1996). In that model, all firms' have constant returns to scale production functions and an interaction between ex ante human capital investments and bilateral search, resulting in social increasing returns to average human capital. In contrast, we explicitly allow for home production and therefore capture the possibility of under-participation and tax-induced wage compression generating mutually reinforcing effects on human capital investments, as will be shown below.
} 
obtain a higher return to human capital investment. It also follows that more skilled workers are more likely to participate in the labor market. This is enough to generate increasing returns to education, at least around the participation margin.

The tax treatment of workers - both as individuals and as couples - varies considerably across countries (OECD, 2001). Differential tax treatment appears to play a considerable role in explaining cross-country heterogeneity in female participation rates and full-time/part-time participation. For example, Jaumotte (2003) uses panel data for 17 OECD countries spanning the period 1985 to 1999 to investigate the determinants of aggregate labor force participation of women aged 25-54 years. She finds a statistically significant negative correlation between female participation and the wedge between the tax rates of second earners and single individuals (measured at an earnings level of $67 \%$ of the average production wage), ceteris paribus.

These results provide supporting evidence for the observation motivating this paper, namely that taxes and social security payments directly affect the participation decision. Our model shows how this can lead to under-participation and consequently have important indirect effects on individuals' decisions to invest in acquiring skills.

\section{The Model}

There are two periods. A representative worker is born in the first period with ability $a$ and has expectations of future home productivity $b$. By investing in education in the first period, the worker can increase second period workplace productivity to $\alpha \geq a$. The cost of any such investment is $c_{a}[\alpha-a]$ where $c_{a}>0$. Assume that high ability types have a lower cost to acquiring workplace skills; i.e. $a>a^{\prime}$ implies $c_{a} \leq c_{a^{\prime}}$. Home productivity $b$ is determined in the second period and is considered as a random draw from $F$ with finite support $[\underline{b}, \bar{b}]$. For simplicity assume education does not affect the return to home production.

Given productivities $(\alpha, b)$ in the second period, the worker has a unit time endowment which is allocated between production at home and in the workplace. If a worker with productivity $\alpha$ supplies $l$ units of labor to the workplace, a competitive labor market implies the worker earns $(\alpha w) l$ where $\alpha w$ is the market wage for a worker with productivity $\alpha$. Second period labour 
market income is taxed; if a worker earns income $\alpha w l$ then after tax income is

$$
y=S+(1-\tau) \alpha w l
$$

where $S>0$ are social security benefits paid to individuals, and $\tau \in[0,1]$ is the effective marginal rate of income tax. Note, $S / \tau$ defines a break even level of income, where workers whose pre-tax earnings $y_{0}$ are less than this amount receive a social security payment $S-\tau y_{0}$ from the government, while those earning more pay tax $\tau y_{0}-S$ to the government. Assuming a constant marginal tax rate is a convenient simplification. Given after tax income $y$, the worker consumes $C=y / p$ units of a consumption good, where we normalise the price of that good $p=1$.

The utility in the second period through consuming $C$ units of the consumption good and $h$ units of home production is $U_{2}(C, h) \cdot{ }^{3}$ For ease of exposition we assume $U_{2}$ is additively separable; i.e.

$$
U_{2}(C, h)=u(C)+b x(h)
$$

where $u, x$ are both increasing, concave and differentiable functions.

As the budget constraint implies $C=S+(1-\tau) \alpha w l$ and the time constraint implies $h=1-l$, the worker's second period labor supply problem reduces to choosing $l \in[0,1]$ to maximise

$$
U_{2}=u(S+(1-\tau) \alpha w l)+b x(1-l) .
$$

Let

$$
U_{2}^{*}(\alpha ; S, \tau, F)=\int_{\underline{b}}^{\bar{b}}\left[\max _{l \in[0,1]} u(S+(1-\tau) \alpha w l)+b x(1-l)\right] d F(b)
$$

denote expected second period utility given expectations of future home productivity and the optimal labor supply rule. Given ability $a$, the worker in the first period chooses education to maximise

$$
\max _{\alpha \geq a}\left[U_{2}^{*}(\alpha ; .)-c_{a}[\alpha-a]\right] .
$$

\footnotetext{
${ }^{3}$ See inter alia Becker (1965), Gronau (1977), Sandmo (1990), Apps and Rees (1999) and Garibaldi and Wasmer (2004) for models emphasizing the importance of home production. We build on this work by introducing endogenous human capital formation and heterogeneous productivities.
} 
This optimisation problem is not concave as after tax income is convex in $\alpha, l$. We analyse the worker's optimization problem recursively, starting in the second period.

\section{Optimal Labour Supply}

As the second period problem is standard, we briefly describe the optimal labour supply decision. In the second period, the worker's optimal labor supply choice solves

$$
\max _{l \in[0,1]} u(S+(1-\tau) \alpha w l)+b x(1-l) .
$$

Let $l^{*}(\alpha, b ; \tau, S)$ denote the optimal labour supply rule and define the functions

$$
\begin{aligned}
& b_{P T}(\alpha)=\alpha w(1-\tau) u^{\prime}(S) / x^{\prime}(1) \\
& b_{F T}(\alpha)=\alpha w(1-\tau) u^{\prime}(S+(1-\tau) \alpha) / x^{\prime}(0),
\end{aligned}
$$

where concavity of $u$ and $x$ implies $b_{P T}>b_{F T}$. Figures 1a,1b below depict these functions when $u($.$) has constant relative risk aversion.$

As the objective function in (3) is concave in $l$, standard optimisation theory implies the following claim (which we state without proof).

Claim 1. Optimal Labour Supply.

(i) $l^{*}=0$ if $b>b_{P T}$;

(ii) $l^{*}=1$ if $b<b_{F T}$;

(iii) otherwise $l^{*}$ is described by the first order condition

$$
b x^{\prime}\left(1-l^{*}\right)=\alpha w(1-\tau) u^{\prime}\left(S+(1-\tau) \alpha w l^{*}\right)
$$

If home productivity is very high, $b>b_{P T}$, the worker does not participate in the labor market. Conversely if home productivity is very low, $b<b_{F T}$, the worker takes full time employment in the market sector; i.e. $l^{*}=1$. In the part-time region where $b \in\left(b_{F T}, b_{P T}\right)$, optimal labor supply implies $l^{*} \in(0,1)$ and $(4)$ describes the optimal trade-off between home 
production and employment in the market sector. It can be shown that labor supply $l^{*}$ is strictly decreasing in home productivity in the part-time region. The effect of workplace productivity $\alpha$ on labor supply $l^{*}$ is ambiguous and is discussed in detail below (see Claim 2).

\section{Optimal Education}

In the first period, the worker has expectations on future home productivity and anticipates the optimal labor supply decision in the second period. By investing in education to productivity level $\alpha$, the worker obtains expected utility

$$
U_{1}(\alpha ; .) \equiv E_{b}\left[u\left(S+(1-\tau) \alpha w l^{*}\right)+b x\left(1-l^{*}\right)\right]-c_{a}[\alpha-a]
$$

where $l^{*}=l^{*}(\alpha,$.$) is described in Claim 1$ and $b \sim F$. As $l^{*}$ is chosen optimally, the Envelope Theorem implies the change in total utility by increasing productivity is

$$
\frac{d U_{1}}{d \alpha}=M R-c_{a}
$$

where

$$
M R=(1-\tau) w E_{b}\left[l^{*} u^{\prime}\left(S+(1-\tau) \alpha w l^{*}\right)\right]
$$

is the marginal return to education. Not suprisingly, the marginal return to education depends on the after tax wage rate. The more important insight of (5) is that the marginal return to education also depends on expected labor supply. For example, suppose the worker is risk neutral; i.e., $u(C)=c$. Risk neutrality implies $M R=(1-\tau) w E_{b}\left[l^{*}\right]$; i.e. the marginal return to education is proportional to expected labor supply. Risk neutrality also implies $l^{*}$ is increasing in $\alpha$ (use (4) in Claim 1). Hence risk neutrality implies there are increasing returns to education. Workers who expect to participate in full time employment with probability one have the highest marginal return to education. In contrast, workers who expect not to participate in the labor market have a zero marginal return to education.

The case with strictly risk averse workers is more complicated, as risk aversion generates 
income effects on the optimal labor supply choice. ${ }^{4}$ We can make three general observations.

1. Consider $\alpha$ sufficiently low that the worker is non-participant with probability one, which implies $b_{P T}(\alpha)<\underline{b}$. In this case Claim 1 implies $l^{*}=0$ and (5) implies $M R=0$. Hence for productivities $\alpha$ around the non-participant margin, where $b_{P T}(\alpha)=\underline{b}$, there must be increasing returns to education as we move from zero marginal returns to strictly positive returns.

2. Consider $\alpha$ sufficiently high that the worker takes full time employment with probability one, implying $\bar{b}<b_{F T}(\alpha)$. In this case Claim 1 implies $l^{*}=1$ and (5) implies $M R=$ $(1-\tau) w u^{\prime}(S+(1-\tau) \alpha w)$ which is strictly decreasing in productivity $\alpha$. Hence there must be diminishing returns to education for workers who expect to participate in full time employment with certainty.

3. The risk neutral case suggests that increasing returns to education arise when labor supply is increasing in productivity. But with risk averse agents, (5) implies $M R$ has slope:

$$
\frac{\partial[M R]}{\partial \alpha}=(1-\tau) w E_{b}\left[\frac{\partial l^{*}}{\partial \alpha} \cdot\left[u^{\prime}+(1-\tau) \alpha w l^{*} u^{\prime \prime}\right]+(1-\tau) w l^{* 2} u^{\prime \prime}\right]
$$

where the utility functions are evaluated at $c=S+(1-\tau) \alpha w l^{*}$. Note that in the part-time region where $l^{*} \in(0,1)$, the effect of $\frac{\partial l^{*}}{\partial \alpha}$ on the slope of $M R$ is ambiguous and depends on the sign of $\left[u^{\prime}+(1-\tau) \alpha w l^{*} u^{\prime \prime}\right]$. This latter term depends on the degree of relative risk aversion and may be negative. However, note that the optimal labor supply rule is given by (4) and implies

$$
\frac{\partial l^{*}}{\partial \alpha}=w(1-\tau) \frac{u^{\prime}+(1-\tau) \alpha w l^{*} u^{\prime \prime}}{-\left[b x^{\prime \prime}+\alpha^{2} w^{2}(1-\tau)^{2} u^{\prime \prime}\right]}
$$

which is also proportional to $\left[u^{\prime}+(1-\tau) \alpha w l^{*} u^{\prime \prime}\right]$. Hence the bracketed term in (6) is equivalent to

$$
-\frac{\left[b x^{\prime \prime}\left(1-l^{*}\right)+\alpha^{2} w^{2}(1-\tau)^{2} u^{\prime \prime}\right]}{w(1-\tau)}\left[\frac{\partial l^{*}}{\partial \alpha}\right]^{2}+(1-\tau) w l^{* 2} u^{\prime \prime}
$$

\footnotetext{
${ }^{4}$ Risk neutrality implies $U_{2}(C, h)$ is quasi-linear where all income effects go on consumption $C$.
} 
and a sufficient condition for this expression to be positive is

$$
\left|\frac{\alpha}{l^{*}}\left[\frac{\partial l^{*}}{\partial \alpha}\right]\right|>1
$$

If income effects are so strong that (part-time) labor supply decreases with $\alpha$, there are still increasing returns to education if (8) holds. In that case, the worker enjoys the benefit of increased productivity through increased home production rather than through increased labor supply.

\subsection{Characterization of Optimal Education}

To obtain a tighter characterisation of the optimal education choice, we simplify the analysis in two ways. First, assume a CRRA utility function, $u(c)=c^{1-\sigma} /(1-\sigma)$ with strictly risk averse workers $\sigma>0$. Second, assume that $F$ is degenerate, where a worker anticipates future home productivity $b=b_{0}$ with probability one. Our interest now is in understanding how individuals with different expected home productivities have different investment incentives.

The first step is to characterize the optimal labor supply rule with CRRA.

Claim 2. Optimal Labor Supply with CRRA.

(i) If $\sigma<1$ then $l^{*}$ is strictly increasing in $\alpha$ for all $b \in\left(b_{F T}, b_{P T}\right)$. Further $b_{F T}$ is strictly increasing in $\alpha$.

(ii) if $\sigma>1$ then

(a) for low productivities $\alpha<S /[(\sigma-1)(1-\tau) w], l^{*}$ and $b_{F T}$ are both increasing in $\alpha$;

(b) for $\alpha>S /[(\sigma-1)(1-\tau) w], b_{F T}$ is decreasing in $\alpha$. Further, a $b^{c} \in\left(b_{F T}, b_{P T}\right)$ exists where $l^{*}$ is strictly increasing in $\alpha$ for $b \in\left(b^{c}, b_{P T}\right)$ and strictly decreasing in $\alpha$ for $b \in\left(b_{F T}, b^{c}\right]$.

\section{Proof is in the appendix.}

Figures $1 \mathrm{a}$ and $1 \mathrm{~b}$ depict these two cases. Figure 1a describes the thresholds $b_{P T}$ and $b_{F T}$ for low levels of risk aversion, $\sigma<1$. Claim 2 implies labor supply is always increasing in $\alpha$. Figure $1 \mathrm{~b}$ holds when there is high risk aversion, $\sigma>1$. For $\alpha$ high, where $\alpha>S /[(\sigma-1)(1-\tau)]$, $b_{F T}$ is decreasing in $\alpha$ and a $b^{c}>b_{F T}$ then exists where $l^{*}$ is decreasing in $\alpha$ for $b<b^{c}$ and increasing otherwise. Standard comparative statics establish that $b^{c}$ is strictly increasing in $\alpha$. 


\section{Figures 1a, 1b here.}

To obtain a useful characterisation of $M R$, define the functions $\alpha_{P T}(b)$ and $\alpha_{F T}(b)$ as

$$
\begin{gathered}
\alpha_{P T}=b x^{\prime}(1) /\left[(1-\tau) w u^{\prime}(S)\right] \\
\alpha_{F T} u^{\prime}\left(S+(1-\tau) w \alpha_{F T}\right)=b x^{\prime}(0) /[(1-\tau) w]
\end{gathered}
$$

where $\alpha_{F T}$ is defined by an implicit function. Note, $\alpha=\alpha_{P T}(b)$ is the inverse function of $b=b_{P T}(\alpha)$ as defined earlier and so corresponds to the locus labelled $b_{P T}$ in Figures 1a and $1 \mathrm{~b}$. $\alpha_{F T}(b)$ is the inverse function of $b=b_{F T}(\alpha)$ and corresponds to the locus labelled $b_{F T}$. Clearly if $\sigma>1$, then $\alpha_{F T}$ does not exist for some $b$ (see Figure 1b); i.e. workers never work full-time if $b$ is large enough. For ease of exposition, we restrict attention to $\sigma \leq 1$ so that $\alpha_{F T}(b)$ exists for all $b \geq 0$, is unique and is a strictly increasing function - see Figure 1a.

With CRRA $(\sigma \leq 1)$ and $b=b_{0}$, then (5) implies:

$$
\begin{aligned}
M R & =0 \text { if } \alpha \leq \alpha_{P T}\left(b_{0}\right) \\
& =(1-\tau) w l^{*} u^{\prime}\left(S+(1-\tau) \alpha w l^{*}\right) \text { if } \alpha \in\left(\alpha_{P T}\left(b_{0}\right), \alpha_{F T}\left(b_{0}\right)\right) \\
& =(1-\tau) w u^{\prime}(S+(1-\tau) \alpha w) \text { if } \alpha \geq \alpha_{F T}\left(b_{0}\right)
\end{aligned}
$$

Figure 2 below graphs $M R$ by productivity $\alpha$, given $b_{0}$. The structure of $M R$ has three distinct phases. For $\alpha \leq \alpha_{P T}\left(b_{0}\right)$, which implies $b_{0} \geq b_{P T}(\alpha)$, the worker does not participate in the labor market ex-post and so the marginal return to education is zero for such $\alpha$. For $\alpha \geq \alpha_{F T}\left(b_{0}\right)$, which with $\sigma \leq 1$ implies $b_{0} \leq b_{F T}(\alpha)$, the individual takes full time employment with probability one. (5) then implies $M R=(1-\tau) w u^{\prime}(S+(1-\tau) \alpha w)$ and so $u$ strictly concave implies there are diminishing marginal returns to education in the full-time employment region. In the part-time region, $\alpha \in\left(\alpha_{P T}, \alpha_{F T}\right), M R$ depends on expected labor supply $l^{*}$. There are increasing returns to education for $\alpha$ around the non-participant margin, $\alpha=\alpha_{P T}$. However as earnings increase with $\alpha$, the marginal utility of consumption decreases and so it is not necessarily the case that $M R$ is increasing over the entire part-time region. For ease of exposition, we shall assume $M R$ is single peaked in this region. Although $M R$ is continuous in 
$\alpha$ (as labor supply is continuous) its slope is not continuous at the margins $\alpha_{P T}, \alpha_{F T}$ as $\partial l^{*} / \partial \alpha$ is constrained equal to zero outside of the part-time region. ${ }^{5}$

\section{Figure 2 here.}

Given this characterization of $M R$, we can now describe the optimal education decision of a worker given ability $a$ and expected home productivity $b_{0}$. Recall that the worker's problem is

$$
\max _{\alpha \geq a}\left[U_{2}^{*}\left(\alpha, b_{0}\right)-c_{a}[\alpha-a]\right]
$$

where $M R \equiv \partial U_{2}^{*} / \partial \alpha$. The necessary conditions for optimality imply either a corner solution

(i) $\alpha=a$ and $\operatorname{MR}\left(a, b_{0}\right) \leq c_{a}$;

or an interior optimum

(ii) $\alpha=\alpha^{*}\left(a, b_{0}\right)$ where $\operatorname{MR}\left(\alpha^{*}, b_{0}\right)=c_{a}$.

Assuming that $M R$ is single-peaked, as drawn in Figure 2, there are two candidate optimal solutions. A local maximum occurs where $M R\left(\alpha, b_{0}\right)=M C_{a}$ on the decreasing portion of the marginal revenue curve and we let $\alpha^{*}\left(a, b_{0}\right)$ denote that solution. The second candidate maximum is that the worker chooses zero education where such a choice can only be optimal if $\operatorname{MR}\left(a, b_{0}\right) \leq c_{a}$.

Consider then workers with ability $a$ such that $M R\left(a, b_{0}\right)<c_{a}$; e.g. workers with $a<$ $\alpha_{P T}\left(b_{0}\right)$ for whom $M R=0$. With increasing returns to education, these workers compare the value of no education, $\alpha=a$, against educating up to $\alpha=\alpha^{*}\left(a, b_{0}\right)$. Define

$$
V\left(a, b_{0}\right)=\int_{a}^{\alpha^{*}}\left(M R\left(\alpha ; b_{0}, .\right)-c_{a}\right) d \alpha
$$

If $V>0$ the optimal education choice implies $\alpha=\alpha^{*}(a,$.$) as it generates positive value relative$ to no education. $V<0$ implies the converse; the worker is better off choosing no education $\alpha=a$. The optimal investment choice therefore depends on the sign of $V$.

Figure 2 depicts the case when a critical ability $a^{c}$ exists where $V\left(a^{c}, b_{0}\right)=0$. A worker with

\footnotetext{
${ }^{5}$ For $\sigma>1$, Figure 1b implies the worker never works full time if $b_{0}$ is large enough. The properties of $M R$ however are qualitatively identical to the case $\sigma \in(0,1)$ as drawn in Figure 2 ; there are zero returns for $\alpha$ in the non-participation region, increasing marginal returns in the early part of the part-time region (as labor supply increases with $\alpha$ ) and decreasing marginal returns for large enough $\alpha$ (though the full-time region may not exist).
} 
ability $a=a^{c}$ and home productivity $b_{0}$ is indifferent between no education and education to $\alpha^{c}=\alpha^{*}\left(a^{c}\right)$, where indifference requires that the two shaded areas are equal. Note that $a^{c}$ can only occur on the increasing portion of the marginal revenue curve, and so $a^{c}<\alpha_{F T}$.

Assuming such a critical ability worker exists, consider $V\left(a, b_{0}\right)$ for $a<a^{c}$. Differentiating $V$ with respect to $a$ implies

$$
\frac{\partial V}{\partial a}=\left(c_{a}-M R\left(a, b_{0}\right)\right)-\frac{d c_{a}}{d a}\left[\alpha^{*}-a\right]
$$

As $c_{a}$ is non-increasing in $a$ by assumption and there are increasing marginal returns for $a \leq a^{c}$, this implies $\partial V / \partial a>0$ for $a<a^{c}$. As $V\left(a^{c},.\right)=0$ we then have $V<0$ for $a<a^{c}$ and so these workers strictly prefer no education. Further we have $\frac{\partial V}{\partial a}>0$ at $a=a^{c}$ and so $V>0$ for $a>a^{c}$. Hence we have established the following.

Proposition 1. If an ability $a^{c}<\alpha_{F T}$ exists where $V\left(a^{c}, b_{0}\right)=0$ then

(i) workers with ability $a<a^{c}$ choose $\alpha=a$ (no education)

(ii) workers with ability $a>a^{c}$ choose $\alpha=\alpha^{*}(a) \gg a$.

Proposition 1 establishes that, with increasing returns to education, investment choices may be discontinuous in ability. Low ability types with $a<a^{c}$ choose no education and, as $a^{c}<\alpha_{F T}$, these workers either do not participate in the labor market, or only take part-time employment. Workers with sufficiently high ability however choose investment $\alpha^{*}>a$ and, if $\alpha^{*}>\alpha_{F T}$ as drawn in Figure 2, participate ex post in full time employment. Of course it is the high returns due to full time employment which makes the ex ante education decision worthwhile.

We discuss the welfare implications of this result in the next section. For reasons that will become clear, we refer to workers with abilities $a \leq a^{c}\left(b_{0}\right)$ as being caught in a skills underinvestment trap - such workers do not invest in education and have low participation rates in the market sector. Proposition 2 shows how this critical ability depends on home productivity.

Proposition 2. Skills Underinvestment Trap.

$a^{c}\left(b_{0}\right)$ is increasing in $b_{0}$. 
Proof. Recall $V$ is defined by

$$
V\left(a, b_{0}\right)=\int_{a}^{\alpha^{*}}\left(M R\left(\alpha, b_{0}\right)-c_{a}\right) d \alpha
$$

and $a^{c}$ is defined as the solution to $V\left(a, b_{0}\right)=0$. Differentiating with respect to $b_{0}$ yields

$$
\frac{\partial V}{\partial b_{0}}=\int_{a}^{\alpha^{*}} \frac{\partial\left[M R\left(\alpha, b_{0}\right)\right]}{\partial b_{0}} d \alpha .
$$

Now (9) implies $\partial[M R] / \partial b_{0}=0$ outside of the part-time region. In the part-time region $\alpha \in\left(\alpha_{P T}, \alpha_{F T}\right),(4)$ in Claim 1 implies that $l^{*}$ is strictly decreasing in $b_{0}$. Further CRRA with $\sigma \leq 1$ implies

$$
\frac{\partial}{d l^{*}}\left[l^{*} u^{\prime}\left(S+(1-\tau) \alpha w l^{*}\right)\right]=\frac{S+(1-\sigma)(1-\tau) \alpha w l^{*}}{\left[S+(1-\tau) \alpha w l^{*}\right]^{\sigma+1}}>0 .
$$

(9) and $\sigma<1$ now imply $\partial[M R] / \partial b_{0}<0$ in the part-time region. Hence it follows that $\partial V / \partial b_{0}<0$ for all $a<\alpha_{F T}$. As we have already shown that $\partial V / \partial a>0$ at $a=a^{c}$, the definition of $a^{c}$ and the Implicit Function Theorem now imply $a^{c}$ increases with $b_{0}$.

In the skills underinvestment trap, workers compare the payoff of choosing no education to investing up to productivity $\alpha=\alpha^{*} \gg a$. An increase in home productivity increases the opportunity cost of working in the market sector and so lowers the average return to education. Hence workers with greater home productivity are more likely to be caught in the skills underinvestment trap.

\section{Policy Discussion}

We first consider the comparative static predictions from altering the policy parameters of the model, and then examine the model's welfare implications.

\subsection{Comparative Statics}

Proposition 3 below summarizes how individuals' educational investments are distorted by the tax program $(S, \tau)$ affecting labor income. As the variables $(S, \tau)$ were held fixed in the previous 
section, we denoted the critical ability level as $a^{c}\left(b_{0}\right)$. We now extend that notation and denote that critical ability level as $a^{c}\left(b_{0} ; S, \tau\right)$. Also denote the marginal return to education, given by (9), as $M R\left(\alpha, b_{0} ; S, \tau\right)$.

Proposition 3. The Effect of Social Security and Income Tax on Education; $\sigma \in(0,1)$. $a^{c}\left(b_{0}: S, \tau\right)$ is strictly increasing in $S$ and $\tau$.

Proof: Using the extended notation, recall that $a^{c}$ solves $V\left(a, b_{0} ; S, \tau\right)=0$ where $V$ is defined by

$$
V\left(a, b_{0} ; S, \tau\right)=\int_{a}^{\alpha^{*}}\left(M R\left(\alpha, b_{0} ; S, \tau\right)-c_{a}\right) d \alpha
$$

Differentiation wrt $S$ yields

$$
\frac{\partial V}{\partial S}=\int_{a}^{\alpha^{*}} \frac{\partial\left(M R\left(\alpha, b_{0} ; S, \tau \cdot\right)\right)}{\partial S} d \alpha
$$

Now (9) with $\sigma<1$ implies $M R$ does not change with $S$ in the non-participant region (it is zero) and is strictly decreasing in $S$ in the part-time ${ }^{6}$ and full-time regions. Hence $\partial V / \partial S<0$. As $\partial V / \partial a>0$ at $a=a^{c}$, the Implicit Function Theorem implies $a^{c}$ increases with $S$.

Similarly

$$
\frac{\partial V}{\partial \tau}=\int_{a}^{\alpha^{*}} \frac{\partial\left(M R\left(\alpha ; b_{0}, S, \tau .\right)\right)}{\partial \tau} d \alpha
$$

(9) with $\sigma<1$ again implies $M R$ does not change in the non-participant region (it is zero) and is strictly decreasing in $\tau$ in the part-time and full-time regions. Hence $a^{c}$ increases with $\tau$.

With increasing returns to education, workers with abilities around the part-time employment margin $\left(\alpha_{P T}\right)$ compare no education - which implies productivity $\alpha=a$ (resulting in low ex-post labor supply) - with investing to productivity $\alpha=\alpha^{*} \gg a$ (resulting in high ex-post labor supply). As an increase in the tax rate reduces the return to switching to full-time work, it is not surprising that this leads directly to lower education and participation rates.

The impact of social security on education incentives is more subtle. By construction of the model, an increase in $S$ (with $\tau$ fixed) implies a one-for-one increase in consumption at all earnings levels, where for high earners it implies an increase in the tax-free level of income (or

\footnotetext{
${ }^{6}$ For $\alpha \in\left(\alpha_{P T}, \alpha_{F T}\right),(4)$ implies $l^{*}$ decreases with $S$ while total earnings, $S+(1-\tau) \alpha l^{*}$ increase. Together these imply that $M R$ falls within the part-time region.
} 
tax allowance) $S / \tau$. The insight is that workers in the skills under-investment trap have low earnings ex post - their labor market productivity is low and they choose low labor supply. As their marginal utility of consumption is relatively high, social security $S$ raises their payoffs more relative to being educated and working full-time with relatively high earnings. The presence of social security benefits therefore lowers the value $V$ of a switch to a higher education level, and so increases $a^{c}$. Note, this disincentive disappears if $u($.$) is linear.$

\subsection{Welfare Implications}

Given the labor market is competitive and there are no externalities by assumption, the marginal social return to investment is simply the private marginal return when $S=\tau=0$. Hence define the marginal social return to education:

$$
S R\left(\alpha, b_{0}\right)=M R\left(\alpha, b_{0} ; 0,0\right)
$$

and let $\alpha^{S}\left(a, b_{0}\right)$ denote the socially efficient investment choice given $a, b_{0}$.

Figure 3 below plots $S R$ and $M R$ for given $S, \tau>0$. The proof of Proposition 3 implies that $M R$ must lie below $S R$, and it can be shown that $\alpha_{P T}, \alpha_{F T}$ lie to the right compared to their values when $S=\tau=0$. Note also that $S R$ must exhibit increasing returns around the participation margin - it is a special case of $M R$.

Recall, $a^{c}$ is the ability threshold where a worker is just indifferent between no education and educating to $\alpha=\alpha^{*}$ given the tax regime $(S, \tau)$. Given there are also increasing social returns to education, let $a^{s}=a^{c}\left(b_{0} ; 0,0\right)$ denote the socially efficient ability threshold between no education and educating to $\alpha^{S}>a$, where Proposition 3 implies $a^{s}<a^{c}$.

\section{Figure 3 here.}

Figure 3 depicts the deadweight losses implied by the tax program for the critical worker with ability $a^{c}$. As $a^{s}<a^{c}$, the socially optimal outcome is that the worker invests to $\alpha^{S}$ where $S R=M C_{a}$. If the worker pursues the positive education decision, and increases productivity to $\alpha^{c}$, then the corresponding deadweight loss due to the tax program is the Harberger triangle labelled $D W L_{2}$. At productivity level $\alpha^{c}$, the worker obtains $M R=(1-\tau) w u^{\prime}(c)$ and the tax 
wedge implies the worker underinvests in education. For workers with higher abilities, $a>a^{c}$, the deadweight loss implied by the tax program corresponds to such Harberger triangles. It is interesting to note in this example that the participation decisions are ex post efficient: the worker takes full time employment which is socially optimal. The efficiency loss is on the ex ante education choice.

Suppose instead the worker with ability $a^{c}$ takes the no education option, $\alpha=a$. Given the worker is indifferent between $\alpha=a$ and $\alpha^{c}$, the additional deadweight loss to this low education decision is the area between $S R$ and $M R$ over productivies $\alpha \in\left[a^{c}, \alpha^{c}\right]$. This additonal area is labelled $\mathrm{DWL}_{1}$ in Figure 3. The large substitution effect induced by increasing marginal returns to education generates a correspondingly large deadweight loss. Of course workers with lower abilities strictly prefer the no education choice.

As is well known in the optimal taxation literature, it is most efficient to tax goods which are traded inelastically. High ability types, who aquire skills and participate full-time in the market sector, invest marginally less with positive income tax rates, but the deadweight loss is a relatively small Harberger triangle. The non-convexity generated by increasing returns to education imply a large substitution effect for workers caught in the skills underinvestment trap. Given a more generous social security system or higher income tax rates, such types switch from $\alpha^{*}$ to no education and low labor supply. This can yield a severe deadweight loss.

\section{Empirical Relevance}

\subsection{Potential applications}

Our model provides three critical insights. The first is that there are increasing returns to education for workers with productivities around the participation margin, where $\alpha=\alpha_{P T}\left(b_{0}\right)$. Workers with productivity less than $\alpha_{P T}\left(b_{0}\right)$ do not participate in the labor market, and so have a zero marginal return to education ex ante. Higher productivity workers choose positive labor supply ex post, which implies a positive marginal return to education ex ante. The special case of risk neutrality implies workers with the highest marginal return to education are those who expect to participate in full time employment with certainty. 
The second insight is that, with increasing returns to education, the optimal education decision of an individual with ability $a$ satisfying $M R\left(a, b_{0}\right)<c_{a}$ is non-marginal. By that we mean the worker compares the payoff to no education (and low labor supply ex-post) against investing to productivity level $\alpha^{*}\left(a, b_{0}\right) \gg a$ (and high labor supply ex-post). Proposition 2 shows that this decision is sensitive to expected home productivity, as that determines the payoff to non-participation in the market sector.

The third insight is that an increase in tax rates reduces the returns from working longer hours and leads to lower education and participation rates. These effects will have greater implications for gender parity in education and participation rates in countries in which taxes on second earners are higher.

What is the empirical relevance of these results? There are at least three possible applications, with perhaps the most obvious relating to child-care. Given that female partners are more likely to look after offspring than male partners, young women may anticipate future childcare responsibilities and hence higher home productivity than men. For this reason, they may be less likely to invest in education and hence less likely to participate in the market sector.

An alternative interpretation is that $U_{2}(C, h)$ describes a simple consumption/leisure tradeoff, where some workers have a greater value of leisure, $b$, than others. Proposition 2 shows that such workers are also more likely to choose low education ex ante and have low participation probabilities ex post. Instead of interpreting $l^{*} \in[0,1]$ as a part-time employment decision, one could instead interpret it as working for fraction $l^{*} \in[0,1]$ of the tax year. In particular, if there are fixed costs to going to work, it may be more efficient to work full-time when employed but only work for fraction $l^{*}$ of the year, rather than working every day but for only a fraction $l^{*}$ of the day. Workers choosing this fractional year option are then characterized as having relatively high quit rates and experiencing extended spells of unemployment. In essence they are choosing low ex post labor supply $l^{*}$, reflecting their productivities at home and in the workplace. $^{7}$

A third application is to criminal activity. Our model thereby extends the recent literature

\footnotetext{
${ }^{7} \mathrm{~A}$ slightly different perspective is that workers with low $b$ have a relatively high value to enjoying the consumption good. Given their more materialistic preferences, these workers are more likely to choose a high level of education and participate in full time employment.
} 
on the economics of crime (for a summary see papers in the 2004 International Economic Review Symposium on crime and the overview by Merlo, 2004). In this context, $b x($.$) might$ be interpreted as the payoff to criminal activities (or work in the informal or untaxed sector) rather than the payoff to home production. Our finding of increasing returns to education implies that low ability types may be caught in a 'crime trap'. Such workers choose not to invest in education and not to participate in the formal labor market, and instead focus on criminal activities.

\subsection{Increasing returns to education}

Next we address the question of whether or not there is any empirial evidence of increasing returns to education once we control for endogenous labour supply. We are not aiming here to provide a full test of the model. Instead our goal is simply to identify the average returns to each educational qualification once hours of work are taken into account, and to distinguish the degree to which these average returns increase with educational qualification. Because men and women typically have - or anticipate having - different responsibilities for child care, we estimate the model separately by gender.

Suppose that the empirical wage and labor supply functions are given by:

$$
\begin{gathered}
w_{i}=\theta^{\prime} X_{2 i}+v_{i} \\
l_{i}=\max \left(0, \theta^{\prime} X_{1 i}+u_{i}\right)
\end{gathered}
$$

where $w_{i}$ is the natural log of the hourly wage rate for market work, $l_{i}$ measures the $i$-th individual's market work hours, and the $X \mathrm{~s}$ are the exogenous variables. Thus $l_{i}$ is always observed but $w_{i}$ is observed only when $l_{i}>0$. This specification is the standard Tobit selection model, discussed in Vella (1992) for example. This selection model involves first estimating a reduced form censored hours equation by Tobit using all observations, and then including the Tobit residuals as an additional explanatory variable in the wages equation that is estimated only for individuals for whom $l_{i}>0$. 
The model is estimated separately for men and women aged between 25 and 59 years. The estimates are reported in Table 1.

\begin{tabular}{|c|c|c|c|c|c|c|}
\hline \multirow[b]{2}{*}{ Variables } & \multicolumn{3}{|c|}{ Women } & \multicolumn{3}{|c|}{ Men } \\
\hline & Hours & Wages $£$ & Means $^{a)}$ & Hours & Wages £ & Means $\left.^{a}\right)$ \\
\hline \multirow[t]{2}{*}{ Higher degree } & 14.83 & 0.825 & 0.038 & 11.39 & 0.697 & 0.051 \\
\hline & $(7.95)$ & $(16.15)$ & & $(5.11)$ & $(15.51)$ & \\
\hline \multirow[t]{2}{*}{ Degree only } & 10.56 & 0.748 & 0.152 & 8.44 & 0.588 & 0.148 \\
\hline & $(8.47)$ & $(20.59)$ & & $(5.16)$ & $(16.80)$ & \\
\hline \multirow[t]{2}{*}{ Teaching, nursing etc } & 7.73 & 0.573 & 0.082 & 10.62 & 0.472 & 0.104 \\
\hline & $(5.21)$ & $(13.44)$ & & $(5.46)$ & $(11.62)$ & \\
\hline \multirow[t]{2}{*}{ Vocational qual } & 1.61 & -0.001 & 0.463 & -1.08 & -0.053 & 0.469 \\
\hline & $(2.33)$ & $(0.06)$ & & $(1.13)$ & $(2.89)$ & \\
\hline \multirow[t]{2}{*}{ A-level } & 7.76 & 0.196 & 0.190 & 8.79 & 0.311 & 0.240 \\
\hline & $(6.30)$ & $(4.38)$ & & $(5.46)$ & $(9.01)$ & \\
\hline \multirow[t]{2}{*}{ O-level } & 8.87 & 0.304 & 0.306 & 8.79 & 0.218 & 0.245 \\
\hline & $(8.05)$ & $(9.18)$ & & $(5.77)$ & $(6.61)$ & \\
\hline \multirow[t]{2}{*}{ CSE } & 5.01 & 0.111 & 0.060 & 8.37 & 0.097 & 0.051 \\
\hline & $(3.26)$ & $(2.46)$ & & $(3.88)$ & $(2.20)$ & \\
\hline \multirow[t]{2}{*}{ Other non-academic } & 5.93 & 0.196 & 0.061 & 9.88 & 0.056 & 0.059 \\
\hline & $(3.91)$ & $(4.38)$ & & $(4.87)$ & $(1.32)$ & \\
\hline \multirow[t]{2}{*}{ Residuals } & & 0.002 & & & -0.007 & \\
\hline & & $(2.76)$ & & & $(9.30)$ & \\
\hline \multirow{2}{*}{$\begin{array}{l}\text { No. of observations } \\
\text { (Pseudo)R-squared }\end{array}$} & 4646 & 3070 & & 3939 & 2743 & \\
\hline & 0.047 & 0.191 & & 0.025 & 0.263 & \\
\hline
\end{tabular}

a) Conditional on being in work. Data from the 2002 wave of the British Household Panel Survey.

Note that this procedure controls for endogeneity of labor supply. The data used are from 
Wave 12 of the British Household Panel Survey (BHPS), conducted in 2002. ${ }^{8}$

There are several points to note about the estimates. First, the estimated coefficient to the Tobit residual term in the female wages equation is positive and statistically significant. This implies that unobservables inducing women to supply more hours of market work - such as productivity in the market sector $(\alpha)$ relative to the home sector $(b)$ - are positively associated with wages. ${ }^{9}$ However for men, the estimated coefficient to the Tobit residual term in the wages equation is negative and statistically significant. Unobservables inducing men to supply more hours of market work are negatively associated with wages.

Second, the estimates show that hours of work and hourly wage rates are increasing with highest educational qualification for both men and women. The base group is no educational qualification. From these estimates, we predicted labor supply and wages separately for women and men at each level of highest educational qualification. These predictions are reported in Table 2. Notice that predicted hours of work are typically increasing in education, as Column [1] of Table 2 shows. Consistent with the model, more highly educated workers choose positive labor supply ex post, which implies a positive marginal return to education ex ante. Note that hourly wages are also increasing in education, consistent with standard human capital theory. However, over and above the insights of human capital theory, the total returns to education should include not just the returns to augmented productivity but also the higher probability of market sector participation, as we argued in previous sections of this paper. The predicted returns are reported in Columns [3] and [6] of Table 2 for women and men respectively.

\footnotetext{
${ }^{8}$ The BHPS reports each individual's highest educational qualification and not years of education. We used the following educational dummy variables in our analysis: Higher degree; First degree; HND/HNC, teach, nurse etc; Vocational qualification; One or more Advanced-level qualification usually taken at age 18; One or more GCSE or Ordinary-level qualification usually taken at aged 16; Certificate of Secondary Education (CSE); Other non-academic qualification; and no qualification (the base).

The censored hours equation included all the educational variables plus dummy variables for health (2), number of children in various age bands (5) and home ownership status. age and its square. The wages equation included all he educational variables, age and its square, and the Tobit residuals.

${ }^{9}$ Our estimates also showed that the returns to education that control for endogeneity of labor supply are in all cases smaller than those that do not. These results - not reported in the interests of space - are available from the authors on request. This suggests that empirical estimates of the returns to education that do not take into account endogenous selection into hours worked will over-estimate the direct returns to education.
} 


\begin{tabular}{l|ccc|ccc}
\hline \hline \multicolumn{1}{c}{ Table 2: Predicted Hours and Wages by Highest Educational Qualification } \\
\hline \multirow{2}{*}{ Variables } & \multicolumn{3}{c}{ Women } & \multicolumn{3}{c}{ Men } \\
& {$[1]$} & {$[2]$} & {$[3]$} & {$[4]$} & {$[5]$} & {$[6]$} \\
& Predicted & Predicted & Hours* & Predicted & Predicted & Hours \\
& Hours & Wages & Wages & Hours & Wages & $*$ Wages \\
\hline Higher degree & 26.108 & 10.145 & 264.87 & 30.307 & 13.105 & 397.173 \\
Degree only & 22.719 & 9.328 & 211.92 & 27.216 & 11.212 & 305.146 \\
Teach/nurse etc & 19.619 & 7.933 & 155.64 & 28.425 & 9.836 & 279.588 \\
Vocational qual & 18.029 & 6.713 & 121.03 & 25.011 & 8.415 & 210.468 \\
A-level & 17.893 & 6.646 & 118.92 & 25.855 & 8.281 & 214.105 \\
O-level & 16.591 & 6.129 & 101.69 & 24.306 & 7.606 & 184.871 \\
CSE & 11.504 & 5.068 & 58.30 & 24.709 & 6.693 & 165.377 \\
Oth. nonacademic & 10.252 & 5.596 & 57.37 & 19.545 & 6.699 & 130.932 \\
& & & & & & \\
\hline \hline
\end{tabular}

Figure 4 presents scatter-plots of predicted weekly hours against hourly wages for women and men. Thus Figure 4a (top panel of figure 4) represents the plot of Column [1] of Table 2 against Column [2], while Figure 4b plots Column [4] of Table 2 against Column [5]. As in Tables 1 and 2, the observations are arranged arranged in ascending order of highest educational qualification. There are striking differences by gender. For women at the lower levels of education, the scatterplot exhibits increasing returns to education, especially from at least one CSE qualification to at least one Ordinary-level qualification and above. At intermediate levels of education (ie above vocational qualifications), the scatterplot for women exhibits decreasing returns. At the highest levels of education (postgraduate qualification), returns are once again increasing. In contrast, for men there is an initial large jump in hours (with no jump in wages) for men with at least one CSE qualification compared to men with other nonacademic qualifications, which might be interpreted as increasing returns to education at the participation margin. But apart from this, the scatterplot does not exhibit the clear pattern of increasing returns at the lower levels of education around the participation margin that is 
visible for women.

In summary, our empirical results do indeed suggest that the returns to education are increasing over some educational levels, especially for women. This arises not just because more education is directly associated with higher wage offers but also because it is associated with a greater participation probability and more hours of work. And at lower levels of education, participation rates and hours of work are much more likely to be zero. In sum, individuals who invest more in education are likely to work longer hours in the market sector and to earn higher hourly wages. Women are also more likely to be characterized by unobservables that increase earnings (such as high $\alpha$ relative to $b$ ). This finding is consistent with our story of relative productivities in the informal and formal sectors affecting labor market outcomes differently for women and men. A challenge for future work is to extend this approach to allow for endogeneity of education in a three equation system.

\section{Conclusion}

In this paper we modeled educational investment and hours of work in a competitive labor market in which heterogeneous workers have different productivities, both at home and in the workplace. We investigated the degree to which there might be under-investment in human capital, and examined the deadweight losses accruing via distortionary taxes. We showed that there are increasing returns to education at the participation margin, and that deadweight losses are most severe for workers located here. Although the social planner's optimum implies a worker should choose a high level of education and participate in the market sector, instead she chooses not to invest in human capital and either non-participation or partial participation in market-sector work. Consequently a severe deadweight loss is generated by this substitution effect. Those individuals most likely to be in this "trap" are those types with large enough home productivity, who may be either involved in home or black market production, or may be characterized by a strong preference for other non-market sector activities. These results suggest that the heterogeneous income tax policy packages characterizing various economies are likely to generate different skills investment incentives for young workers. These are likely to 
have real effects on market economies.

\section{References}

[1] Acemoglu, Daron (1996) "A Microfoundation for Social Increasing Returns in Human Capital Accumulation". The Quarterly Journal of Economics, Vol. 111, No. 3. (Aug., 1996), pp. $779-804$.

[2] Apps PF and R Rees (1999) 'Individual vs. Joint Taxation in Models with Household Production', Journal of Political Economy, 107, 393-403.

[3] Becker, GS (1965). 'A Theory of the Allocation of Time', The Economic Journal, 75, pp. 493-517.

[4] Booth, AL and MG Coles (2004) "Part-time Employment Traps". September.

[5] Garibaldi P and E Wasmer (2004) 'Raising Female Employment: Reflections and Policy Tools'. Journal of the European Economic Asssociation, 3(2-3), pp320-30, April-May.

[6] Gronau, R (1977). "Leisure, Home Production and Work - the Theory of the Allocation of Time Revisited", Journal of Political Economy, 85(6), pp 1099-1124, December.

[7] Jaumotte, Florence (2003) "Female Labour Force Participation: Past Trends and Main Determinants in OECD Countries". Economics Department Working Papers No. 376, Paris: OECD.

[8] Merlo, Antonio (2004). "Introduction to Economic Models of Crime." International Economic Review, 45 (3), 677-679.

[9] OECD Employment Outlook June 2001. Chapter 4: "Balancing Work and Family Life: Helping Parents into Paid Empoyment". Paris: OECD.

[10] Sandmo, Agnar (1990). "Tax Distortions and Household Production", Oxford Economic Papers, New Series, Vol. 42, No. 1, Special Issue on Public Economics. (January), pp. 78-90. 
[11] Vella, F. (1992). "Simple tests for Sample Selection Bias in Censored and Discrete Choice Models," Journal of Applied Econometrics, 7, pp. 413-421. 


\section{Appendix}

Proof of Claim 2.

The definition of $b_{F T}$ and CRRA implies

$$
b_{F T}=\alpha(1-\tau)(S+(1-\tau) \alpha)^{-\sigma} / x^{\prime}(0) .
$$

Differentiating with respect to $\alpha$ yields

$$
\frac{\partial b_{F T}}{\partial \alpha}=\frac{(1-\tau)[S+(1-\sigma)(1-\tau) \alpha]}{x^{\prime}(0)(S+(1-\tau) \alpha)^{\sigma+1}}
$$

and so

$$
\frac{\partial b_{F T}}{\partial \alpha} \gtrless 0 \text { as } S+(1-\sigma)(1-\tau) \alpha \gtrless 0 .
$$

For $b \in\left(b_{F T}, b_{P T}\right),(4)$ implies $\partial l^{*} / \partial \alpha$ is given by

$$
\frac{\partial l^{*}}{\partial \alpha}=\frac{1-\tau}{-b x^{\prime \prime}-\alpha^{2}(1-\tau)^{2} u^{\prime \prime}}\left[u^{\prime}\left(y_{P T}\right)+\alpha(1-\tau) l^{*} u^{\prime \prime}\left(y_{P T}\right)\right]
$$

where $y_{P T}=S+(1-\tau) \alpha l^{*}$. Concavity of $x$ and $u$ implies $\partial l^{*} / \partial \alpha>0$ if and only if $u^{\prime}\left(y_{P T}\right)+$ $\alpha(1-\tau) l^{*} u^{\prime \prime}\left(y_{P T}\right)>0$. CRRA now implies

$$
\frac{\partial l^{*}}{\partial \alpha} \gtrless 0 \text { as } S+(1-\sigma)(1-\tau) \alpha l^{*} \gtrless 0,
$$

where $b \in\left(b_{F T}, b_{P T}\right)$ implies $l^{*} \in(0,1)$.

The statement of the Claim follows from these facts and that $l^{*}$ is strictly decreasing in $b$ for $b \in\left(b_{F T}, b_{P T}\right)$ with $l^{*}=1$ at $b=b_{F T}$ and $l^{*}=0$ at $b=b_{P T} . b^{c}$ is defined where $S+(1-\sigma)(1-\tau) \alpha l^{*}=0$.

Proof of Claim 3..

(i) For given $b_{0}$ and $\sigma \in(0,1)$, the definitions of $\alpha_{P T}, \alpha_{F T}$ imply these values both increase with $S$. Further for $\alpha \in\left(\alpha_{P T}, \alpha_{F T}\right)$, (4) implies $l^{*}$ decreases with $S$ while total earnings, $S+(1-\tau) \alpha l^{*}$ increase. Together these imply that $M R$ falls within the part-time region. It is 
immediate that $M R$ falls with an increase in $S$ in the full-time region.

(ii) The same arguments imply the equivalent result for $\tau$.

$* * * * * * * * * * * * * * * * * * * * * * * * * * * * * * * * * * * * * * * * * * * *$ 
Figure 1: Labor Supply

Figure 1a: $(\sigma<1)$

$b$

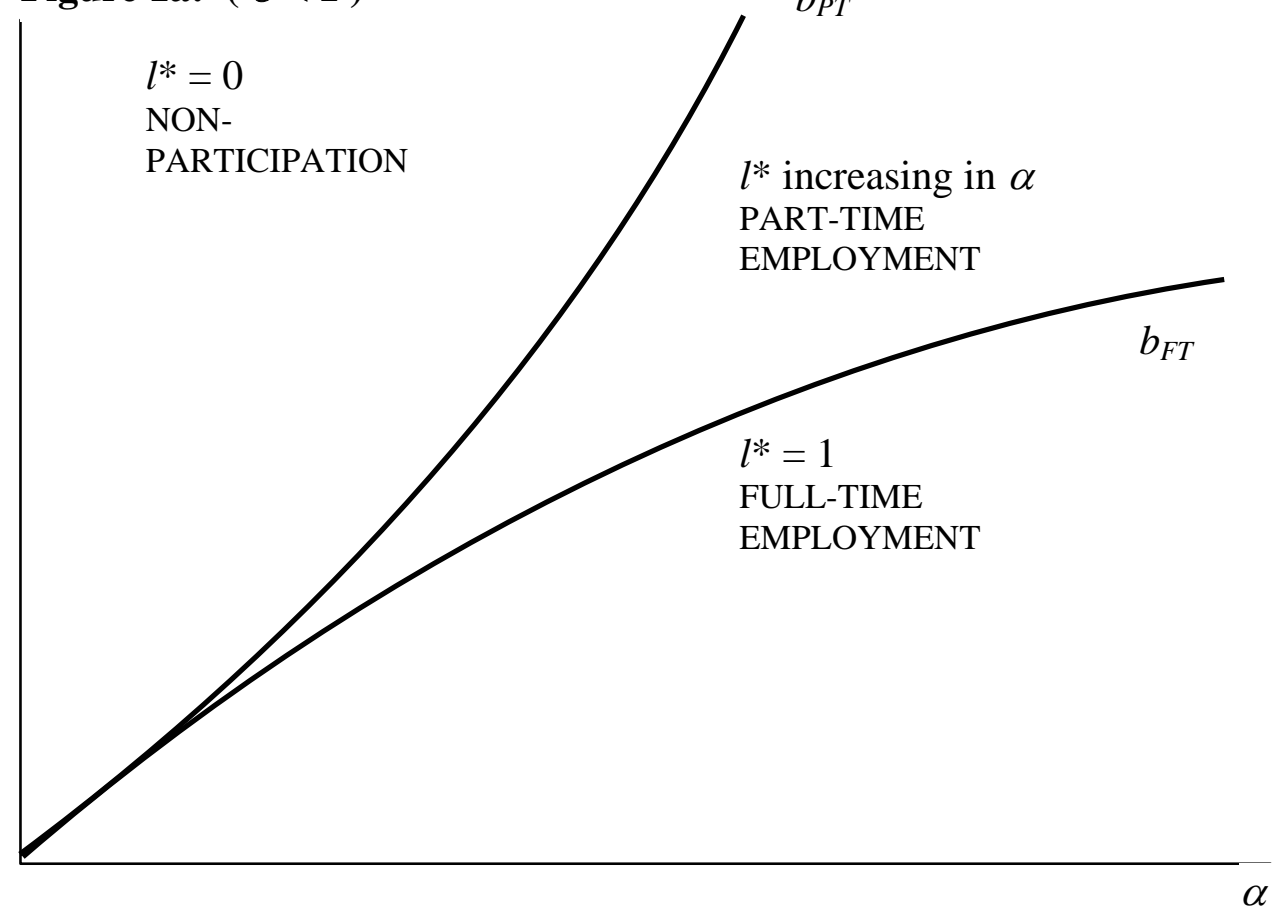

Figure 1b: $(\sigma>1)$

b

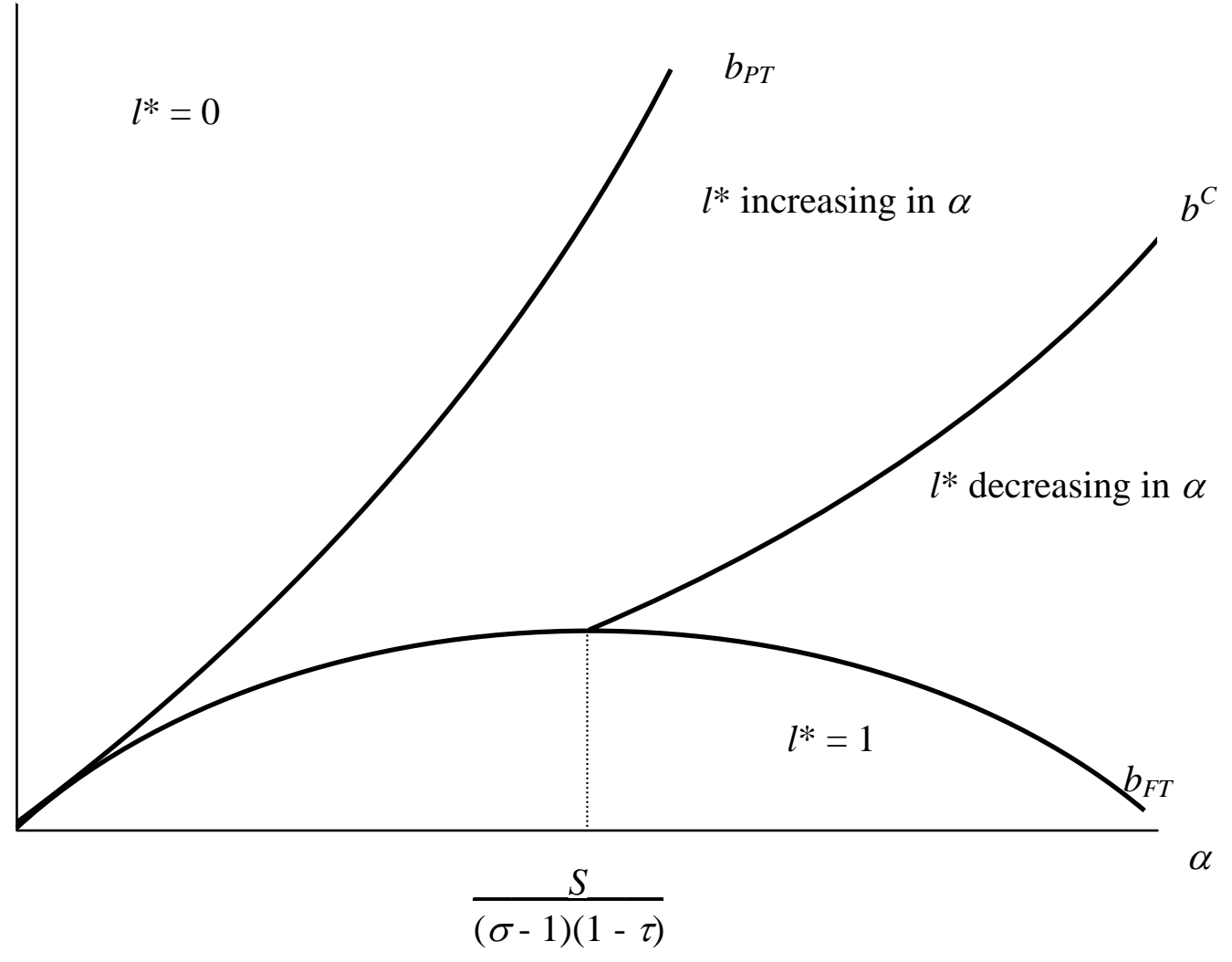


Figure 2: Optimal Education Choice ( $b_{0}$ given)

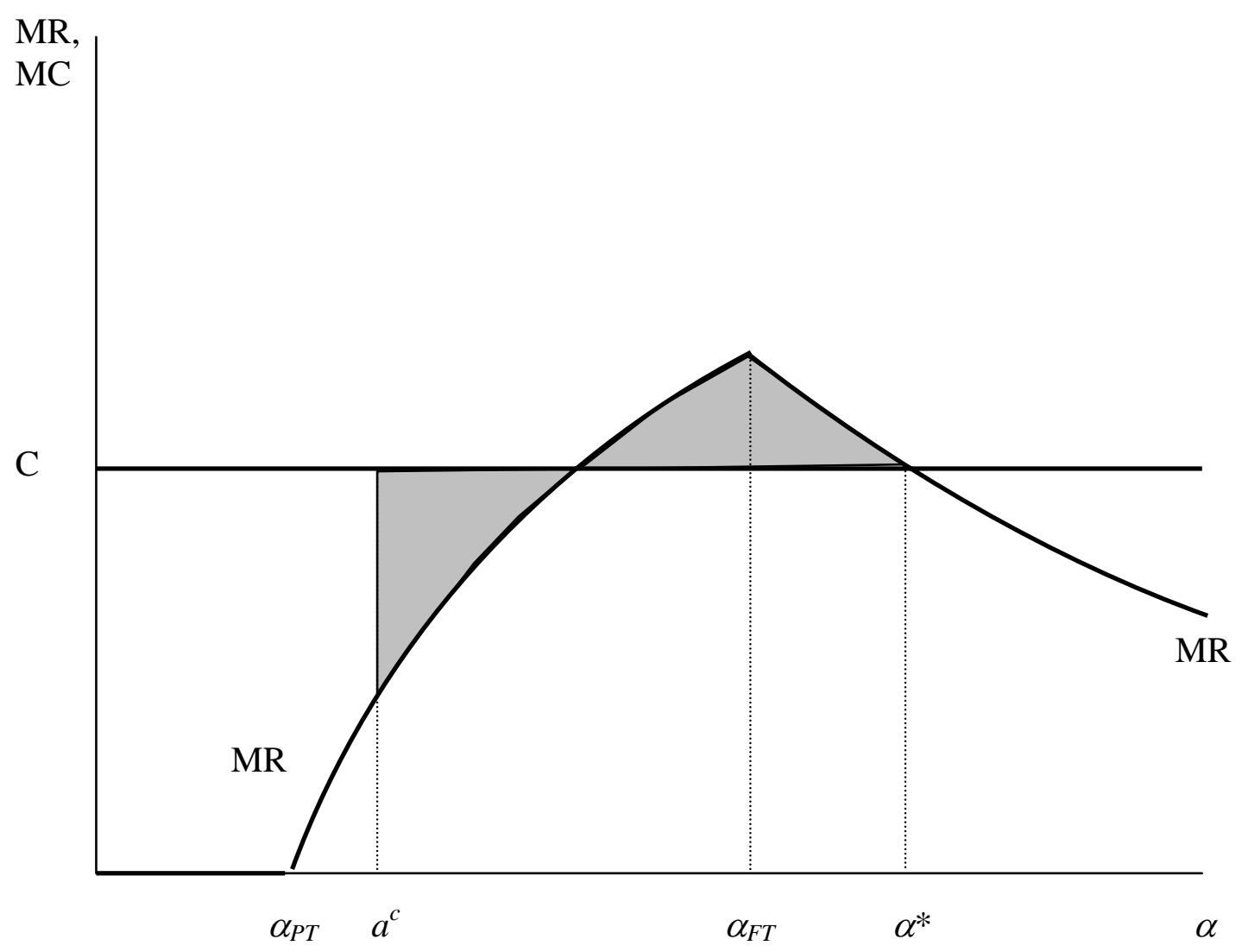


Figure 3: Deadweight Losses

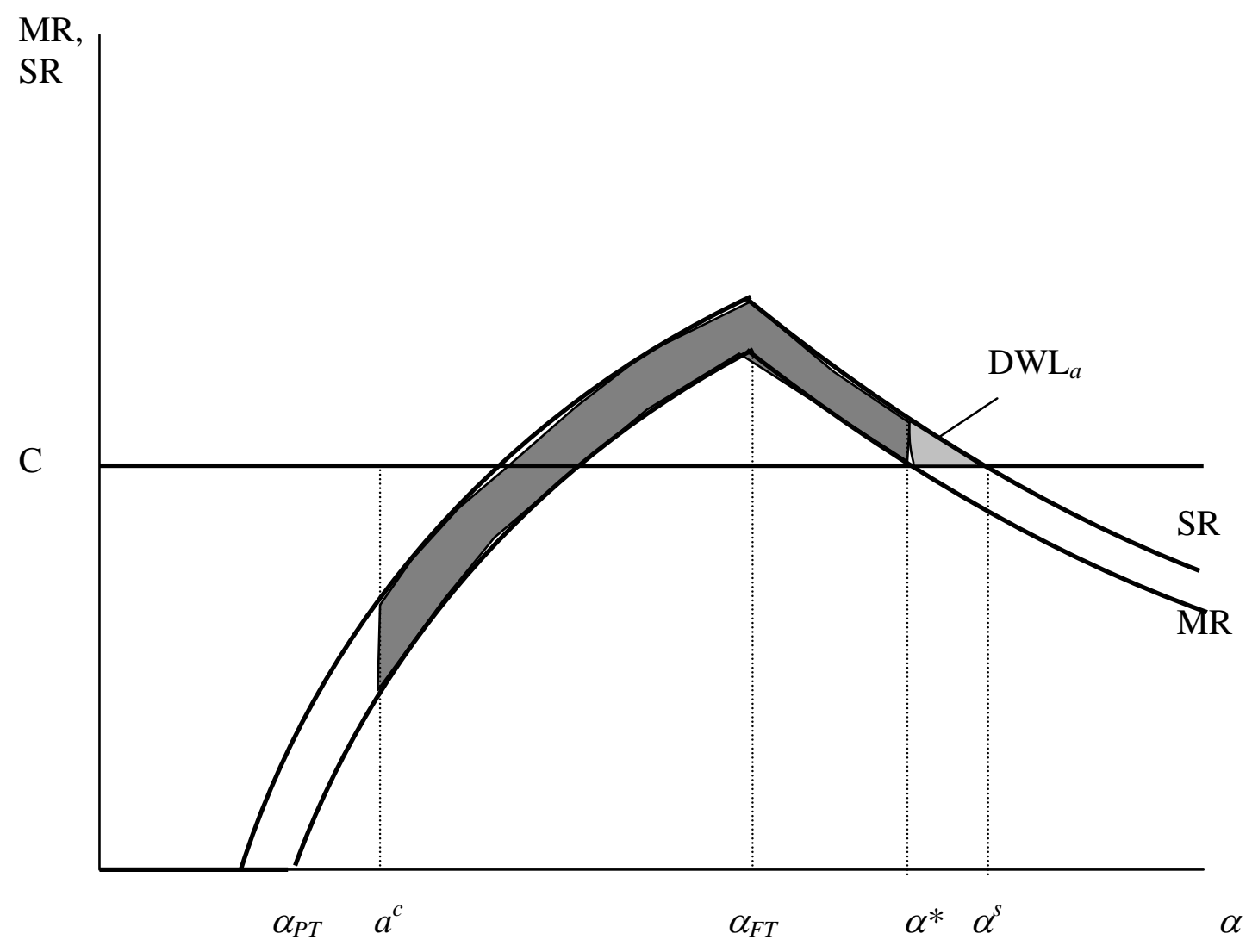


Figure 4: Predicted hours and Wages in Ascending Order of Education, by Gender
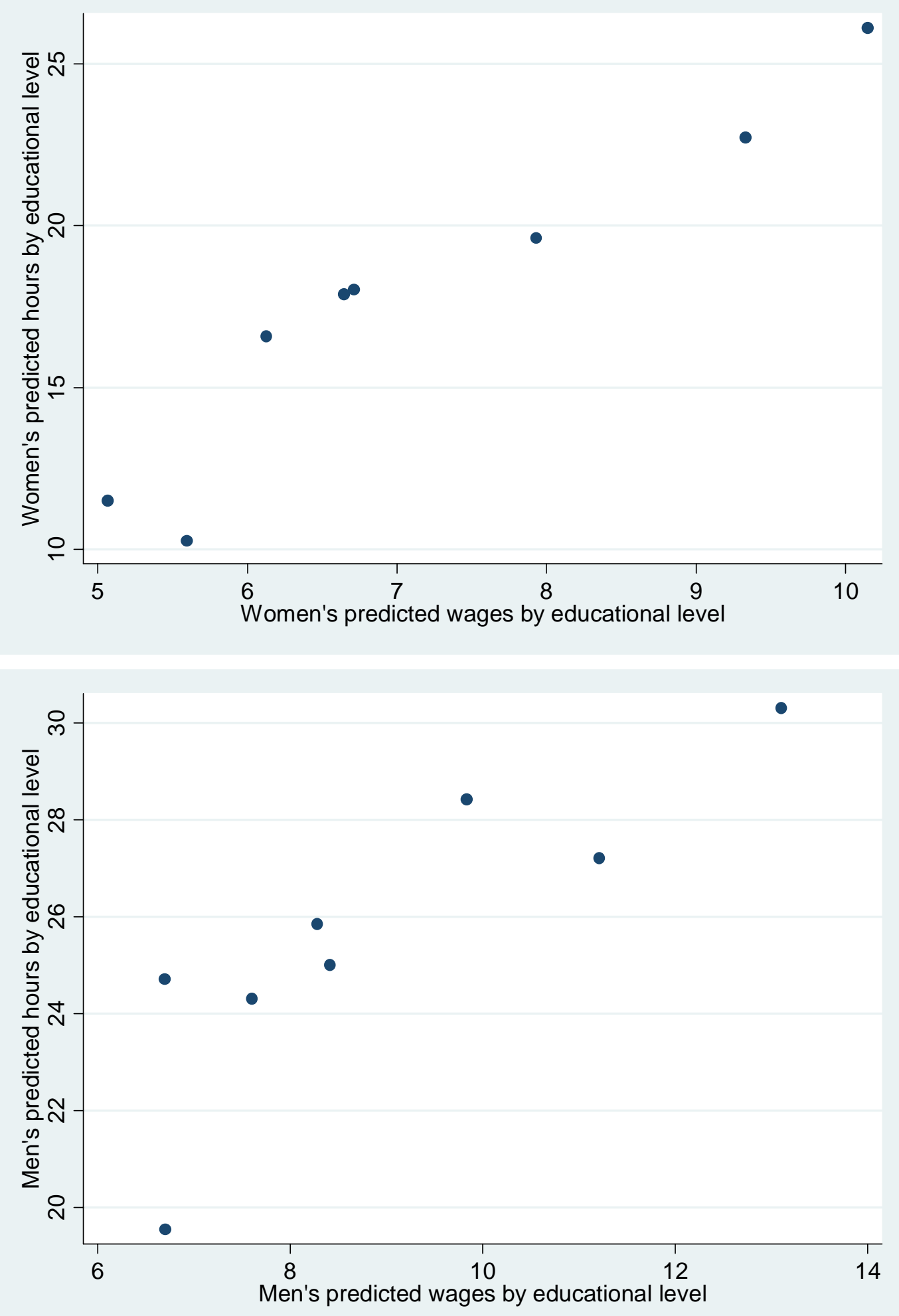